\title{
Les troubles colorectaux neurologiques : une souffrance le plus souvent muette
}

\author{
Neurological colorectal problems: a mostly silent suffering \\ La solution apportée par les laboratoires Coloplast : Peristeen ${ }^{\circledR}$ irrigation transanale
}

C'est l'un des tabous du handicap, et au même titre que l'incontinence urinaire, un problème majeur dans la vie sociale d'une majorité de blessés médullaires : les troubles colorectaux. Deux cas de figure sont répandus, l'incontinence fécale et la constipation. L'incontinence fécale peut réduire à néant les tentatives de socialisation-loisirs, travail, vie amicale et amoureuse, tant celui qui en est victime a peur de « l'accident ». Quant à la constipation (moins de deux selles par semaine), elle peut provoquer des troubles associés, comme des douleurs abdominales ou des nausées. La constipation est aussi souvent associée à certaines infections urinaires notamment avec des germes Escherichia coli.

Les solutions proposées jusque-là réglant l'évacuation des selles pour le blessé médullaire sont les mêmes depuis quelques décades (toucher rectal, évacuation manuelle, laxatif, suppositoire) sans pour autant solutionner le problème des fuites fécales, vécu comme l'épisode le plus dégradant. Il existe pourtant une solution répandue dans d'autres pays européens, comme l'Angleterre ou l'Allemagne : l'irrigation colique rétrograde ou irrigation transanale. L'irrigation transanale consiste à introduire de l'eau dans le rectum (en moyenne $750 \mathrm{ml}$ ), via une sonde à ballonnet, pour vider en quelques minutes toute la partie gauche du côlon et l'ampoule rectale; la manœuvre ne prend en général pas plus d'un quart d'heure. Appelée par nos anciens « lavement », la méthode a beaucoup évolué, jusqu'au système Peristeen ${ }^{\circledR}$ des laboratoires Coloplast (Fig. 1).

Ce système comprend une poche à eau et son bouchon (1 et 2), une unité de contrôle de la pression avec une poire (3 et 4$)$, reliées à une sonde rectale à ballonnet à usage unique (5). Cette sonde, une fois lubrifiée, s'introduit dans le rectum. Par quelques pressions, la poire permet de gonfler le ballonnet dans le rectum, puis d'instiller progressivement l'eau dans les intestins, permettant une vidange de ses selles.

Pour Philippe, l'utilisation de Peristeen ${ }^{\circledR}$ a littéralement changé sa vie : « je suis paraplégique; mon métier de

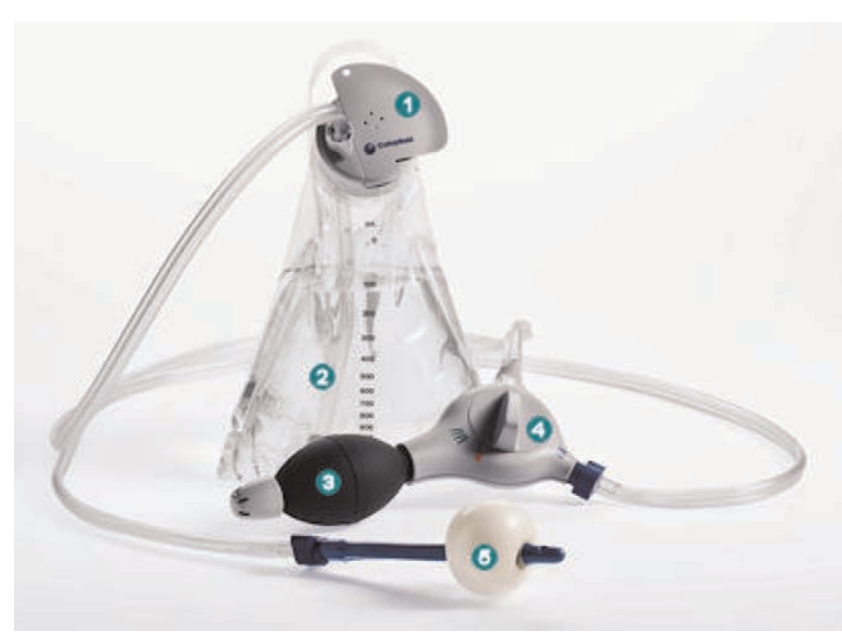

Fig. 1 Système Peristeen ${ }^{\circledR}$ des laboratoires Coloplast

commercial m'oblige à me déplacer souvent et avant d'utiliser ce kit, j'avais régulièrement des problèmes de fuites. J'ai essayé bien des traitements, sans succès. Cela m'a rendu la vie impossible pendant des années ; en dehors de l'aspect « terre à terre » de la souillure et du mal-être généré, ces problèmes d'incontinence fécale rendaient mon métier impossible. Bien sûr, il faut une petite période d'adaptation ; mais pouvoir choisir où et quand je vais vider mes intestins a complètement changé ma vie $»$.

Mis sur le marché depuis novembre dernier par les laboratoires Coloplast, le système Peristeen ${ }^{\circledR}$ ne se prescrit qu'en centre de rééducation, car il nécessite une formation avant son utilisation. Entièrement remboursé, il représente une alternative sûre à un problème dont on parle peu et qui empoisonne la vie de milliers de blessés médullaires. Au même titre que le sondage intermittent, l'irrigation transanale peut devenir, avec le temps, le traitement de référence dans la prise en charge des troubles colorectaux. 